\title{
Integridade em pesquisa e má conduta científica: Diretrizes internacionais, normas nacionais e estudos em cooperação. Reflexões éticas e legais
}

\author{
Research integrity and scientific misconduct: International guidelines, national standards and \\ cooperative research. Ethical and legal reflections \\ Integridad de la investigación y mala conducta científica: Directrices internacionales, estándares \\ nacionales y estudios cooperativos. Reflexiones éticas y legales
}

\author{
Mônica da Costa Serra \\ ORCID: https://orcid.org/0000-0001-8820-2982 \\ Universidade Estadual Paulista "Júlio de Mesquita Filho", Brasil \\ E-mail: monica.serra@unesp.br \\ Valéria Pavão Penteado \\ ORCID: https://orcid.org/0000-0003-4356-1396 \\ Universidade Estadual Paulista "Júlio de Mesquita Filho", Brasil \\ E-mail: valeriapvo@hotmail.com \\ Aline Cristina Senna Barbosa \\ ORCID: https://orcid.org/0000-0001-8867-7830 \\ Universidade Estadual Paulista “Júlio de Mesquita Filho”, Brasil \\ E-mail: barbosa_acs@icloud.com \\ Clemente Maia da Silva Fernandes \\ ORCID: https://orcid.org/0000-0002-5401-6265 \\ Universidade Estadual Paulista "Júlio de Mesquita Filho", Brasil \\ E-mail: c.face@ terra.com.br
}

\begin{abstract}
Resumo
A integridade da pesquisa científica é um mote de crucial importância, quando se fala de investigação científica, e que vem recebendo cada vez mais atenção, seja dentro da Academia, seja na sociedade em geral. No Brasil, a legislação criminal protege, por exemplo, os direitos de autor, tipificando como crime a violação de direito autoral. Agências de fomento à pesquisa científica, como o Conselho Nacional de Desenvolvimento Científico e Tecnológico $(\mathrm{CNPq})$ e a Fundação Amparo à Pesquisa do Estado de São Paulo (FAPESP) elaboraram guias de boas práticas na pesquisa. São várias as formas da denominada má conduta científica. Esta pode ter uma abrangência maior ou menor dependendo da região ou delimitação legislativa considerada. Este trabalho realizou um levantamento de diretrizes internacionais e normas nacionais sobre a integridade em pesquisa e má conduta científica em vários países. Verificou que, apesar de diretrizes internacionais estabelecidas, é notório que o entendimento sobre princípios da integridade em pesquisa e sobre o que é considerado má conduta científica diverge entre diferentes (e muitas vezes vizinhos) países. Com pesquisas sendo cada vez mais desenvolvidas em cooperações internacionais, isto pode gerar consequências diversas para o mesmo fato, ou fatos semelhantes - que podem serem considerados como má conduta científica ou desrespeito à integridade da pesquisa em um país e não em outro. Ou ainda: a sanção aplicada pode ser mais severa em um local do que em outro. Além disso, alguns pesquisadores trabalhando em um mesmo projeto, em cooperação internacional, podem ser punidos em seus países de origem, e outros não. Esta é uma situação de questionamento ético, bioético e legal que precisa de respostas.

Palavras-chave: Bioética; Biodireito; Integridade em pesquisa; Ética em pesquisa; Má conduta científica; Direito civil; Direito penal; Direito internacional comparado; Ciências forenses.
\end{abstract}

\begin{abstract}
Research integrity is a subject of crucial importance when it comes to scientific investigation, and has been receiving more and more attention, both within the Academy and in society in general. In Brazil, for example, criminal legislation protects copyright, defining copyright infringement as crime. Research funding agencies, such as the National Council for Scientific and Technological Development (CNPq) and the São Paulo Research Foundation (FAPESP) have drawn up guides to good practices in research. There are several forms of the so-called scientific misconduct. This may have a larger or smaller scope depending on the region or legislative delimitation considered. This work carried out a survey of international guidelines and national standards on research integrity and scientific
\end{abstract}


misconduct in several countries. It found that, despite established international guidelines, it is clear that the understanding about research integrity principles and what is considered scientific misconduct differ between different (and often neighboring) countries. With research being more and more developed in international cooperation, this can generate different consequences for the same fact, or similar facts - which can be considered as scientific misconduct or disrespect for research integrity in one country and not in another. Or: the applied sanction may be more severe in one place than in another. Furthermore, some researchers, working on the same project, in international cooperation, may be punished in their countries of origin, and others do not. This is a situation of ethical, bioethical and legal questioning that needs answers.

Keywords: Bioethics; Biolaw; Research integrity; Ethics in research; Scientific misconduct; Civil law; Criminal law; Comparative international law; Forensic sciences.

\section{Resumen}

La integridad de la investigación científica es un tema de crucial importancia cuando se trata de investigación científica, y que ha recibido cada vez más atención, tanto dentro de la Academia como en la sociedad en general. En Brasil, la legislación penal protege, por ejemplo, los derechos de autor, tipificando la infracción de derechos de autor como un delito. Agencias de promoción de la investigación científica, como el Consejo Nacional de Desarrollo Científico y Tecnológico (CNPq) y la Fundación de Apoyo a la Investigación del Estado de São Paulo (FAPESP) han elaborado guías de buenas prácticas en investigación. Hay varias formas de mala conducta científica. Esta puede tener un mayor o menor alcance dependiendo de la región o delimitación legislativa considerada. Este trabajo llevó a cabo una búsqueda de directrices internacionales y estándares nacionales sobre integridad de la investigación y mala conducta científica en varios países. Encontró que, a pesar de las pautas internacionales establecidas, está claro que la comprensión de los principios de integridad en la investigación y lo que se considera mala conducta científica difiere entre países diferentes (y a menudo vecinos). Dado que la investigación se desarrolla cada vez más en la cooperación internacional, esto puede generar diferentes consecuencias por el mismo hecho, o hechos similares, que pueden ser considerados como mala conducta científica o falta de respeto a la integridad de la investigación en un país y no en otro. O bien: la sanción aplicada puede ser más severa en un lugar que en otro. Además, algunos investigadores que trabajan en un mismo proyecto, en cooperación internacional, pueden ser sancionados en sus países de origen y otros no. Se trata de una situación de cuestionamiento ético, bioético y jurídico que necesita respuestas.

Palabras clave: Bioética; Bioderecho; Integridad de la investigación; Ética de la investigación; Mala conducta Científica; Derecho civil; Derecho penal; Derecho internacional comparado; Ciencias forenses.

\section{Introdução}

A integridade na pesquisa pode ser entendida como a adesão a normas éticas e profissionais comumente aceitas na condução de pesquisas e em tomar decisões responsáveis, quando dilemas éticos se apresentarem (Resnik et al., 2017). É um mote de crucial importância, quando se fala de investigação científica, e que vem recebendo cada vez mais atenção, em âmbito mundial, seja dentro da Academia, seja na sociedade em geral, inclusive com amplo destaque na mídia.

O conceito de (ausência de) integridade em pesquisa não se confunde com o de má conduta científica; a segunda é parte do leque abrangido pela primeira. A má conduta científica envolve falsificação, fabricação/manipulação de dados e plágio (estas são consideradas as formas mais severas, apesar de existirem outras). Pode ser entendida, em um sentido muito geral, como uma violação das normas éticas amplamente aceitas no meio científico (Nature, 2019; Bülow, Helgesson, 2019; Resnik et al., 2017; Shamoo, Resnik, 2015; Fundação de Amparo à Pesquisa do Estado de São Paulo, 2014).

As instituições de pesquisa devem capacitar os pesquisadores a agir de acordo com os padrões de uma boa pesquisa (Bouter, 2020; Li, Cornelis, 2020; Fundação de Amparo à Pesquisa do Estado de São Paulo, 2014). Não obstante, agências de fomento à pesquisa e revistas científicas têm papéis importantes a desempenhar neste contexto (Bouter, 2020).

De acordo com o Código de Boas Práticas da Fapesp (Fundação de Amparo à Pesquisa do Estado de São Paulo, 2014):

As instituições de pesquisa compartilham com os pesquisadores individuais a responsabilidade pela preservação da integridade ética da pesquisa científica. Elas são as responsáveis principais pela promoção de uma cultura de boa conduta científica entre os pesquisadores e estudantes a ela vinculados, assim como pela prevenção, investigação e punição de más condutas científicas que ocorram em seu âmbito. 
Larigot (2019) destaca o fato de que é fundamental que os pesquisadores estejam conscientes de sua responsabilidade e as consequências que seu trabalho pode produzir na sociedade e no meio ambiente. Além disso, a autora questiona a responsabilidade institucional referente a eventuais más condutas de seus pesquisadores.

Diante deste cenário, realizamos um levantamento de diretrizes internacionais e normas nacionais sobre a integridade em pesquisa em vários países, estabelecendo também reflexões e questionamentos éticos e legais.

\section{Metodologia}

Este estudo centrou-se no levantamento e análise de diretrizes internacionais e normas nacionais sobre a integridade em pesquisa. Como se baseou em dados secundários e públicos, não se insere nas regras de obrigatoriedade de submissão e aprovação por Comitê de Ética em Pesquisa envolvendo seres humanos.

O presente trabalho apresenta um estudo descritivo, do tipo teórico-reflexivo, realizado a partir da leitura de diretrizes, normas e literatura sobre o tema, aproximando-se da abordagem qualitativa (Pereira et al., 2018).

\section{Resultados e Discussão}

A má conduta científica e a integridade da pesquisa estão em extremidades opostas: a primeira está na extremidade antiética e a última está na extremidade ética (Shamoo, Resnik, 2015).

$\mathrm{O}$ mote da integridade da pesquisa tem ganhado destaque mundial por meio de cobertura da mídia, bem como do debate político de como fomentá-la (Armond et al., 2021; Silva, Coelho, 2020; Davies, 2019; Anderson, 2018; Araújo, 2017). É considerado parte da epistemologia social da ciência (Resnik, Elliott, 2019).

\subsection{Conceitos de integridade em pesquisa}

Apesar de termos como "honestidade", "responsabilidade" e "objetividade", o entendimento a respeito do conceito de integridade em pesquisa não é uníssono entre pesquisadores de diferentes partes do mundo, institutos de pesquisa/universidades e empresas. Atos semelhantes têm sido entendidos e julgados de modo diverso e diferentes países ou por diferentes personagens (O'Gradymar, 2021; Desmond e Dierickx, 2021; Moher et al., 2020; Davies, 2019; Bülow, Helgesson, 2019; Anderson, 2018; Bonn et al., 2017; Godencharle, 2014). Agir de acordo com o conceito de integridade na pesquisa vai além de não cometer atos de má conduta.

Anderson (2018) credita os diferentes entendimentos sobre integridade em pesquisa a experiências pessoais com pesquisa, nacionalidades, local de trabalho e posição hierárquica na academia, causando diferentes perspectivas sobre o que constitui a integridade da pesquisa e o que é mais importante na manutenção da credibilidade da ciência.

A integridade em pesquisa subdivide-se em duas dimensões: a individual (do pesquisador) e a institucional (da instituição de pesquisa). Neste sentido, o pesquisador deve respeitar os seguintes princípios: honestidade intelectual, responsabilidade, respeito, imparcialidade e transparência. As instituições de pesquisa, por sua vez, devem proporcionar um ambiente que promova a conduta responsável por parte dos pesquisadores (Fundação Osvaldo Cruz, 2019).

Recentemente, tem ganhado destaque uma situação cuja influência na integridade da pesquisa vem sendo discutida: o vazamento de dados de pesquisa clínica (Rajkumar e Sampathkumar, 2020). Sobretudo em tempos de pandemia da covid-19, o vazamento de informações para o público em geral, muitas vezes sem fundamentação científica, ou mesmo o vazamento de dados parciais, sem contextualização, pode provocar consequências diversas - desde a valorização, no mercado financeiro, do fabricante de um medicamento, até danos à saúde de pessoas desavisadas. Mas isto pode acontecer também em relação a pesquisas de fármacos para o tratamento de outras patologias. Neste sentido, vazamentos ameaçam a integridade em pesquisa. 
Research, Society and Development, v. 10, n. 9, e46110918219, 2021

(CC BY 4.0) | ISSN 2525-3409 | DOI: http://dx.doi.org/10.33448/rsd-v10i9.18219

\subsection{Conceitos de má conduta científica}

São reconhecidos como principais e mais graves atos de má conduta a falsificação, a fabricação de dados e o plágio FFP (Bouter, 2020; Nature, 2019; Fundação Osvaldo Cruz, 2019; National Academies of Sciences, Engineering, and Medicine, 2017; Resnik et al., 2017; Shamoo, Resnik, 2015; Fundação de Amparo à Pesquisa do Estado de São Paulo, 2014). O erro científico cometido de boa fé e divergências honestas em matéria científica não são considerados má conduta científica (National Academies of Sciences, Engineering, and Medicine, 2017; Resnik et al., 2017; Fundação de Amparo à Pesquisa do Estado de São Paulo, 2014).

A falsificação é conceituada como correspondendo à manipulação de materiais, equipamentos ou processos de pesquisa ou alteração ou omissão de dados ou resultados de modo que a pesquisa não seja apresentada com precisão - ou seja, a intencionalmente deturpar dados; a fabricação corresponde à invenção de dados ou casos e registrá-los ou relatá-los, e plágio como à apropriação de ideias, processos, resultados ou palavras de outrem, sem dar-lhe o devido crédito (Fundação Osvaldo Cruz, 2019; Resnik et al., 2015; Fundação de Amparo à Pesquisa do Estado de São Paulo, 2014; Godecharle et al., 2014).

Tijdink et al. (2016) realizaram um estudo junto a 535 cientistas holandeses, sobre má conduta científica, por meio da aplicação de questionários. Apresentaram 22 itens considerados como má conduta (classificados como moderados, severos e graves), perguntando se os participantes se, e com que frequência, haviam realizado. Verificaram, entre outros, que 89 pesquisadores responderam que já haviam deixado de publicar parte dos resultados de estudos, 322 haviam incluído autores em publicações que não se qualificavam para autoria, 92 decidiram excluir dados após verem os resultados, e 71 empregaram ideias ou frases de outrem, sem a devida citação.

\subsection{Criminalização}

A criminalização da prática de má conduta por parte de pesquisadores (como falsificação, fabricação e plágio) tem sido mote de discussão, inexistindo consenso sobre a questão (Bülow, Helgesson, 2019; Godencharle, 2014). Trata-se de questão legislativa nacional - em que cada país decide autonomamente sobre o assunto. Assim, alguns países entendem como condutas criminosas as mesmas que, em outros, são restritas a questões administrativas, de autorregulação da ciência.

Apesar de a definição de casos de conduta com crimes ser dependente de legislações nacionais, na seara da Bioética há correntes favoráveis e desfavoráveis à criminalização da ciência. Alguns autores argumentam que crimes devem ser cometidos intencionalmente, com o afã de prejudicar outrem - o que não deve ser o caso de quem comete má conduta científica. Entendem ainda que as consequências de uma condenação penal são negativas também para os familiares e dependentes da pessoa privada de sua liberdade (Bülow, Helgesson, 2019).

Há autores que defendam a criminalização de más condutas consideradas "graves" - os atos tipicamente considerados como má conduta: fabricação, falsificação e plágio (FFP). Não obstante, há outras ações entendidas como má conduta mais "leve", que não entrariam no rol de condutas tipificadas, como apresentação seletiva de resultados e análise estatística inadequada (Bülow, Helgesson, 2019).

Nos Estados Unidos e no Reino Unido, más condutas como falsificação e fabricação são criminalmente tipificadas, e há casos de pesquisadores presos por terem falsificado e fabricado dados científicos. Nos Países Baixos, conhecido ficou um caso de investigador condenado a 120 horas de serviço comunitário (Godencharle, 2014). A China intensificou os esforços para policiar a integridade científica com novas regulamentações, introduzindo potenciais punições criminais por más condutas científicas consideradas sérias, como fraude (Jia, 2018).

Pickett e Roche (2018) realizaram uma pesquisa para verificar a opinião de pessoas leigas (indivíduos adultos, norteamericanos), alheias à comunidade científica, sobre criminalização de duas situações que envolvem má conduta científica: 1 . 
fraude de dados (falsificação ou fabricação); 2. relato de pesquisas seletivos (manipulação de dados - falha em relatar todos os resultados de pesquisas ou decisões metodológicas e analíticas que influenciam os resultados). Os autores verificaram que $66 \%$ dos respondentes eram favoráveis à criminalização de falsificação ou fabricação e 37\% de relatos de pesquisas seletivos. No que diz respeito a penalidades aplicáveis, a multa foi apontada por $65 \%$ dos respondentes para falsificação ou fabricação de dados e por $79 \%$ para relatos de pesquisas seletivos. Para a primeira modalidade, prisão por até 01 ano foi indicada por $22 \%$ dos respondentes, e por mais de 1 ano por 13\%. Para a segunda situação, prisão por até 01 ano foi indicada por $10 \%$ dos respondentes, e por mais de 1 ano por $11 \%$.

No Brasil, a legislação protege os direitos do autor. O Código Penal brasileiro (Brasil, 1940), em seu artigo 184, apresenta a tipificação do crime de violação de direito autoral, cujo caput está a seguir transcrito:

Art. 184. Violar direitos de autor e os que lhe são conexos:

Pena - detenção, de 3 (três) meses a 1 (um) ano, ou multa.

Não obstante, há que se destacar que plágio e violação de direito autoral não são sinônimos, não constituindo o mesmo fato. Eventualmente, em uma mesma ação, ambos podem estar presentes. Mas isto não é regra geral.

\subsection{Integridade em pesquisa e instituições de pesquisa}

Resnik e Elliott (2019) entendem que as organizações de pesquisa desempenham um papel fundamental na promoção da integridade científica. Os autores afirmam que:

As organizações podem promover a causa da integridade da pesquisa desenvolvendo, implementação e aplicação de regras, políticas e procedimentos que normas de suporte para investigação e fornecendo o material e humano recursos necessários para uma boa ciência.

Mejlgaard et al. (2020) propuseram nove tópicos, a serem seguidos por institutos de pesquisa e universidades, para implementarem a cultura da integridade em pesquisa, a seguir descritos:

1. Ambiente de pesquisa: garantir procedimentos de avaliação justos e evitar hipercompetição e pressão excessiva para publicar.

2. Orientação e mentoria: estabelecer diretrizes claras para orientação de pós-graduação (como a frequência de reuniões); realizar treinamento de habilidades e mentoria.

3. Treinamento de integridade: realizar treinamento e aconselhamento confidencial para todos os pesquisadores.

4. Estruturas éticas: estabelecer procedimentos de revisão que acomodem diferentes tipos de pesquisa e disciplinas.

5. Violações de integridade: estabelecer procedimentos que protejam tanto denunciantes como acusados de má conduta.

6. Práticas e gestão de dados: fornecer treinamento, incentivos e infraestrutura para administrar e compartilhar dados.

7. Colaboração de pesquisa: estabelecer regras sólidas para um trabalho transparente com a indústria e parceiros internacionais.

8. Declaração de conflitos de interesses: declarar conflitos (financeiros e pessoais) em pesquisa, revisão e outras atividades profissionais.

9. Publicação e divulgação: respeite as diretrizes de autoria e garantir abertura e clareza no engajamento público. 
Entendimentos sobre a importância do papel das organizações de pesquisa, no sentido de não somente fomentar a disseminação e implementação da cultura da integridade da pesquisa, como também de rever suas políticas de cobrança, incentivo e premiação dos pesquisadores, têm ganhado força.

Discussões sobre integridade em pesquisa focadas apenas nos comportamentos dos indivíduos, sem incorporar ou refletir sobre injustiças mais amplas no sistema da ciência, correm o risco de serem ignoradas pelos próprios pesquisadores aos quais se dirigem (Davies, 2019)

\subsection{Diretrizes internacionais sobre integridade em pesquisa}

Há poucas décadas, o interesse e o questionamento sobre integridade em pesquisa têm ganhado notoriedade mundial, com a divulgação de casos de má conduta científica de grande repercussão.

Em nível internacional, algumas iniciativas, relativas ao estabelecimento de diretrizes, foram tomadas, e estão vigentes. Vale salientar, entretanto, que tais diretrizes não têm força de lei. Podem ser adotadas por organizações de fomento à pesquisa e por periódicos científicos, por exemplo, no sentido de somente proporcionar financiamento ou publicar trabalhos que as respeitem. Mas, em termos legais, os Estados precisam sancionar normas próprias.

A II Conferência Mundial sobre Integridade em Pesquisa, realizada em Singapura, em 2010, aprovou a Declaração de Singapura sobre Integridade em Pesquisa - DSIP (Singapore Statement on Research Integrity, 2010). Representantes de 51 países (pesquisadores, representantes de editores de publicações científicas, de organizações de pesquisa e de agências de fomento) participaram da elaboração deste documento. Esta Declaração é referência internacional sobre o assunto. Estabelece 5 princípios e enumera 14 responsabilidades.

A Declaração de Singapura sobre Integridade em Pesquisa é bastante ampla, contemplando um grande universo de variáveis (Simões, 2018).

Os princípios estabelecidos pela Declaração de Singapura sobre Integridade na Pesquisa são: honestidade, responsabilidade, respeito, imparcialidade, justiça e boa gestão.

As responsabilidades apresentadas na DSIP são:

1. integridade,

2. obediência às normas,

3. emprego de metodologia apropriada,

4. documentação da pesquisa,

5. divulgação de resultados,

6. autoria devida,

7. publicação de agradecimentos,

8. responsabilidade de pareceristas,

9. conflitos de interesse,

10. participação em discussões públicas sobre pesquisa,

11. denuncia de má conduta científica,

12. providências relativas a casos confirmados de má conduta científica,

13. ambientes institucionais que fomentem condutas de integridade em pesquisa,

14. responsabilidade social. 
Apesar de, quantitativamente, a Declaração de Singapura sobre Integridade na Pesquisa apresentar poucos princípios e responsabilidades, os mesmos são bastante abrangentes. O texto da DSIP é curto, mas a hermenêutica de seu conteúdo é bastante ampla. Não obstante, não se trata de documento regulatório, sendo responsabilidade dos personagens participantes de atividades científicas adotarem-no, estabelecendo normas próprias, com as devidas responsabilidades e responsabilizações.

A III Conferência Mundial sobre Integridade em Pesquisa, realizada em Montreal, em 2013, aprovou a Declaração de Montreal sobre integridade em pesquisa e colaborações em investigações que cruzam fronteiras (Montreal Statement on Research Integrity in Cross-Boundary Research Collaborations, 2013). Esta Declaração trata especificamente de situações de cooperação internacional de pesquisa, enumerando 20 responsabilidades dos envolvidos. Tais responsabilidades estão agrupadas de acordo com as seguintes 4 temáticas: responsabilidades gerais, responsabilidades de gestão, responsabilidades nas relações colaborativas e responsabilidades relativas aos resultados das pesquisas.

A VI Conferência Mundial sobre Integridade em Pesquisa, realizada em Hong Kong, em 2019, aprovou os Princípios de Hong Kong (Hong Kong Principles, 2019), a saber:

1. avaliar práticas de pesquisa responsáveis,

2. valorizar relatos de pesquisa completos,

3. recompensar a prática da ciência aberta,

4. reconhecer uma ampla gama de atividades de pesquisa,

5. reconhecer outras tarefas essenciais, como revisão por pares e mentoria.

Moher et al. (2020) apresentaram justificativas para cada um dos cinco Princípios de Hong Kong, como também ilustraram casos em que os mesmos foram ou estão sendo implementados. Os autores apresentam a redação completa de cada princípio:

Princípio 1: Avaliar os pesquisadores em relação a práticas responsáveis desde a concepção até a publicação da pesquisa,

Princípio 2: Valorizar o relato preciso e transparente da totalidade da pesquisa, independentemente dos seus resultados.

Princípio 3: Valorizar as práticas da ciência aberta (pesquisa aberta) - como métodos, materiais e dados abertos.

Princípio 4: Valorizar ampla gama de pesquisas e atividades acadêmicas responsáveis, como replicação, inovação, translação, síntese e metapesquisa.

Princípio 5: Valorizar uma série de outras contribuições para pesquisa e atividade acadêmica responsável, como revisão por pares para financiamentos e publicações, orientação, divulgação e troca de conhecimentos.

O Código Europeu de Conduta para a Integridade em Pesquisa - CECIP (The European Code of Conduct for Research Integrity, 2017) foi publicado em 2017 pela ALLEA - Federação Europeia das Academias de Ciências e Humanidades. Academias de 38 diferentes países são membros desta Federação. Este Código tem sido divulgado nas comunidades científicas europeias. O mesmo não é vinculativo, e cada país tem autonomia para estabelecer as próprias normas e diretrizes. A adesão às diretrizes estabelecidas por este Código não têm sido uniforme em diferentes países europeus. Somente Bulgária e Luxemburgo adotaram-no. Porém, fabricação, falsificação e plágio de dados e resultados são considerados como má conduta científica por todos os países envolvidos. (O’Gradymar, 2021; Desmond e Dierickx, 2021). 
Este Código estabelece 4 princípios: confiabilidade, honestidade, respeito e responsabilidade. Define 8 boas práticas na pesquisa, explicando cada uma delas:

1. Ambiente de pesquisa;

2. Formação, supervisão e orientação;

3. Procedimentos de pesquisa;

4. Salvaguardas;

5. Práticas e gestão de dados;

6. Trabalho colaborativo;

7. Publicação e divulgação;

8. Revisão, avaliação e edição.

O CECIP estabelece ainda o que considera má conduta na pesquisa e outras práticas inaceitáveis. As consideradas principais e mais graves são fabricação, falsificação e plágio. Não obstante, são apresentadas outras 13 práticas inaceitáveis. O Código afirma que as formas mais graves devem ser sancionáveis. Estabelece diretrizes para o tratamento de violações e alegações de má conduta, considerando os princípios da integridade e equidade.

\subsection{Normas nacionais sobre integridade em pesquisa e má conduta científica}

Apesar da existência de diretrizes internacionais, Códigos e Declarações não são vinculativos, cabendo a cada país estabelecer as suas próprias regras sobre o assunto.

Normas estabelecidas por países europeus têm divergido entre si (O’Gradymar, 2021; Desmond e Dierickx, 2021). Países de outras regiões do globo que possuem regras definidas sobre integridade em pesquisa tampouco são totalmente uníssonos com diretrizes internacionais.

Na Europa, 24 dos 32 países possuem normas nacionais sobre integridade em pesquisa. Entre os que não as elaboraram, Bulgária e Luxemburgo explicitamente adotaram o Código Europeu de Conduta para a Integridade em Pesquisa. Grécia e Eslovênia sinalizaram intenção de elaborar normas nacionais. Malta, Liechtenstein, Chipre e Islândia não se manifestaram sobre o assunto (Desmond e Dierickx, 2021).

Desmond e Dierickw (2021) analisaram 20 normas nacionais europeias sobre integridade em pesquisa e compararamnas com o Código Europeu de Conduta para a Integridade em Pesquisa. Verificaram que nenhum dos documentos analisados adotava integralmente os conceitos de integridade em pesquisa do CECIP, havendo mesmo uma grande divergência de conceitos. O único consenso ocorreu em relação à inclusão do FFP como má conduta científica.

Alguns documentos nacionais são referências internacionais, como é o caso do Reino Unido: "Política de Pesquisa e Inovação do Reino Unido e Diretrizes sobre Governança de Boa Conduta de Pesquisa" (UK Research and Innovation, 2013). Este documento define o que considera boa conduta na pesquisa científica, apresenta diretrizes para a efetivação da boa conduta, define condutas inaceitáveis e estabelece diretrizes para reportar e investigar condutas inaceitáveis.

O UK Research Integrity Office, uma organização independente que apoia a comunidade acadêmica e científica em boas práticas e integridade científica, também possui diversas publicações sobre este mote, como o Código de Prática para Pesquisa (UK Research Integrity Office, 2009). Entre outras publicações, em outubro de 2020, em função da pandemia do Sars-CoV-2, publicou "Checklist recomendada para comunidades de pesquisa durante a pandemia de COVID-19: para pesquisas pré-existentes e novas" (UK Research Integrity Office, 2020). 
Nos Estados Unidos, o Escritório de Integridade em Pesquisa (Office of Research Integrity - ORI) supervisiona e dirige as atividades de integridade de pesquisa do Serviço de Saúde Pública em nome do Secretário de Saúde e Serviços Humanos, com exceção das atividades regulamentares de integridade de pesquisa da Food and Drug Administration - FDA. Honestidade, precisão, eficiência e objetividade são os valores compartilhados. Desde 2000, a má conduta científica é definida pelo governo federal norte-americano como fabricação, falsificação ou plágio na proposição, execução ou revisão de pesquisas ou em relatos de resultados de pesquisas. Não obstante, as instituições de pesquisa têm autonomia para considerar outros comportamentos como má conduta, além do FFP (United States, 2020; National Academies of Sciences, Engineering, and Medicine, 2017; Resnik et al., 2015; Steneck, 2007; United States, 2000).

Um estudo realizado por Resnik et al. (2015) analisou as políticas sobre má conduta científica de 183 instituições de pesquisa (incluindo universidades) norte-americanas. Os autores verificaram que 59\% das instituições analisadas consideravam má conduta outros comportamentos além do FFP, que é definido pelo governo federal. Dentre outros, eram considerados má conduta: uso indevido de informações confidenciais $(15,8 \%)$, autoria antiética que não seja plágio $(14,2 \%)$, outro engano envolvendo manipulação de dados (13,1\%) e apropriação indébita de bens/furto (10,4\%).

Na China, em 30 de maio de 2018, normas editadas pelo Partido Comunista e pelo Conselho de Estado atribuíram responsabilidade direta do Ministério da Ciência e Tecnologia em investigar, punir e regulamentar os casos de má conduta em ciências naturais. Nos últimos anos, a ciência chinesa testemunhou uma série de casos de má conduta de grande visibilidade, que resultaram em várias retratações em publicações científicas. Agências de pesquisa do governo chinês possuem normas rígidas que reivindicam uma política de tolerância zero contra severa desonestidade acadêmica, incluindo a determinação de que os registros de integridade dos cientistas sejam verificados ao analisar seus pedidos de bolsas (Jia, 2018)

Li e Cornelis (2020) realizaram um estudo comparando normas de má conduta científica de 21 universidades chinesas com as normas de 22 universidades europeias. Verificaram que, além de falsificação, fabricação e plágio, há outras diferentes formas de má conduta científica previstas, que em muito diferem entre as instituições analisadas. Entre outros dados, observaram que 21 universidades chinesas incluíram plágio e falsificação como más condutas, o que ocorreu com 14 universidades europeias. Fabricação foi citada por 20 instituições chinesas e por 14 europeias. A seguir estão apresentados os números de universidades chinesas e europeias que, respectivamente, incluíram em suas normas: autoria indevida: 21 e 9, violação de confidencialidade: 10 e 4, revisão antiética: 6 e 0 , violações a pesquisas envolvendo seres humanos ou animais: 2 e 5, condução inadequada de conflito de interesses: 0 e 3 ,

No Brasil, o Conselho Nacional de Desenvolvimento Científico e Tecnológico - CNPq elaborou as Diretrizes básicas para a integridade na atividade científica, resultantes do trabalho da Comissão de Integridade da Atividade Científica, constituída em 2011, que possuía atribuições gerais e específicas voltadas à prevenção, educação e investigação da integridade da pesquisa realizada e/ou publicada por pesquisadores em atividade no Brasil. (Conselho Nacional de Desenvolvimento Científico e Tecnológico, 2011). Foram estabelecidas 21 diretrizes, a seguir transcritas:

1. O autor deve sempre dar crédito a todas as fontes que fundamentam diretamente seu trabalho.

2. Toda citação in verbis de outro autor deve ser colocada entre aspas.

3. Quando se resume um texto alheio, o autor deve procurar reproduzir o significado exato das ideias ou fatos apresentados pelo autor original, que deve ser citado.

4. Quando em dúvida se um conceito ou fato é de conhecimento comum, não se deve deixar de fazer as citações adequadas. 
5. Quando se submete um manuscrito para publicação contendo informações, conclusões ou dados que já foram disseminados de forma significativa (p.ex. apresentado em conferência, divulgado na internet), o autor deve indicar claramente aos editores e leitores a existência da divulgação prévia da informação.

6. Se os resultados de um estudo único complexo podem ser apresentados como um todo coesivo, não é considerado ético que eles sejam fragmentados em manuscritos individuais.

7. Para evitar qualquer caracterização de autoplágio, o uso de textos e trabalhos anteriores do próprio autor deve ser assinalado, com as devidas referências e citações.

8. O autor deve assegurar-se da correção de cada citação e que cada citação na bibliografia corresponda a uma citação no texto do manuscrito. $\mathrm{O}$ autor deve dar crédito também aos autores que primeiro relataram a observação ou ideia que está sendo apresentada.

9. Quando estiver descrevendo o trabalho de outros, o autor não deve confiar em resumo secundário desse trabalho, o que pode levar a uma descrição falha do trabalho citado. Sempre que possível consultar a literatura original.

10. Se um autor tiver necessidade de citar uma fonte secundária (p.ex. uma revisão) para descrever o conteúdo de uma fonte primária (p. ex. um artigo empírico de um periódico), ele deve certificar-se da sua correção e sempre indicar a fonte original da informação que está sendo relatada.

11. A inclusão intencional de referências de relevância questionável com a finalidade de manipular fatores de impacto ou aumentar a probabilidade de aceitação do manuscrito é prática eticamente inaceitável.

12. Quando for necessário utilizar informações de outra fonte, o autor deve escrever de tal modo que fique claro aos leitores quais ideias são suas e quais são oriundas das fontes consultadas.

13. O autor tem a responsabilidade ética de relatar evidências que contrariem seu ponto de vista, sempre que existirem. Ademais, as evidências usadas em apoio a suas posições devem ser metodologicamente sólidas. Quando for necessário recorrer a estudos que apresentem deficiências metodológicas, estatísticas ou outras, tais defeitos devem ser claramente apontados aos leitores.

14. O autor tem a obrigação ética de relatar todos os aspectos do estudo que possam ser importantes para a reprodutibilidade independente de sua pesquisa.

15. Qualquer alteração dos resultados iniciais obtidos, como a eliminação de discrepâncias ou o uso de métodos estatísticos alternativos, deve ser claramente descrita junto com uma justificativa racional para o emprego de tais procedimentos.

16. A inclusão de autores no manuscrito deve ser discutida antes de começar a colaboração e deve se fundamentar em orientações já estabelecidas, tais como as do International Committee of Medical Journal Editors.

17. Somente as pessoas que emprestaram contribuição significativa ao trabalho merecem autoria em um manuscrito. Por contribuição significativa entende-se realização de experimentos, participação na elaboração do planejamento experimental, análise de resultados ou elaboração do corpo do manuscrito. Empréstimo de equipamentos, obtenção de financiamento ou supervisão geral, por si só não justificam a inclusão de novos autores, que devem ser objeto de agradecimento.

18. A colaboração entre docentes e estudantes deve seguir os mesmos critérios. Os supervisores devem cuidar para que não se incluam na autoria estudantes com pequena ou nenhuma contribuição nem excluir aqueles que efetivamente participaram do trabalho. Autoria fantasma em Ciência é eticamente inaceitável. 
19. Todos os autores de um trabalho são responsáveis pela veracidade e idoneidade do trabalho, cabendo ao primeiro autor e ao autor correspondente responsabilidade integral, e aos demais autores responsabilidade pelas suas contribuições individuais.

20. Os autores devem ser capazes de descrever, quando solicitados, a sua contribuição pessoal ao trabalho.

21. Todo trabalho de pesquisa deve ser conduzido dentro de padrões éticos na sua execução, seja com animais ou com seres humanos.

As Diretrizes estabelecidas pelo $\mathrm{CNPq}$, em sua maioria, contemplam aspectos relacionados à publicação de resultados de pesquisas científicas.

A Coordenação de Aperfeiçoamento de Pessoal de Nível Superior - CAPES, em janeiro de 2011, recomendou às instituições de ensino públicas e privadas brasileiras que adotassem "políticas de conscientização e informação sobre a propriedade intelectual, adotando procedimentos específicos que visem coibir a prática do plágio quando da redação de teses, monografias, artigos e outros textos por parte de alunos e outros membros de suas comunidades" (Coordenação de Aperfeiçoamento de Pessoal de Nível Superior, 2011).

A Fundação de Amparo à Pesquisa do Estado de São Paulo - FAPESP instituiu o seu Código de Boas Práticas Científicas, que contempla os seguintes temas:

1. Diretrizes para as atividades científicas,

2. Más condutas científicas,

3. Responsabilidade das instituições de pesquisa,

4. Alegação, investigação e declaração de más condutas científicas.

Além do FFP, a FAPESP considera como má conduta científica "prestar, de má-fé ou por negligência, falsa informação sobre a ocorrência de possíveis más condutas científicas”.

A Revista Pesquisa FAPESP, de periodicidade mensal, possui uma seção denominada "Ética", com a coluna "Boas Práticas", voltada para assuntos relacionados à integridade e ética em pesquisa (Revista FAPESP, 2021).

Diversas universidades e sociedades científicas brasileiras, além de agências de fomento, instituíram normas e diretrizes relativas à integridade e ética em pesquisa. Além disso, há normas específicas sobre pesquisas envolvendo seres humanos, estabelecidas por meio das Resoluções do Conselho Nacional de Saúde 466/12, 510/16 e outras resoluções complementares (Brasil, 2012; Brasil, 2016) e animais, estabelecidas pela lei federal n. 11.794/08 (Brasil, 2008).

\section{Considerações Finais}

A preocupação com o mote da integridade em pesquisa é notoriamente crescente em todo o mundo, sobretudo devido à repercussão de denúncias de más condutas científicas pela mídia. A sociedade civil, os governos e a comunidade acadêmica são partes interessadas no respeito aos princípios da integridade em pesquisa e à boa conduta científica.

Em tempos de pandemia do Sars-CoV-2, esta preocupação tende a se acirrar, direcionada sobretudo a pesquisas envolvendo fármacos para o tratamento da covid-19 e a vacinas.

Porém, apesar de diretrizes internacionais estabelecidas, é notório que o entendimento sobre princípios da integridade em pesquisa e sobre o que é considerado má conduta científica diverge entre diferentes (e muitas vezes vizinhos) países. Com pesquisas sendo cada vez mais desenvolvidas em colaborações internacionais, isto pode gerar consequências diversas para o 
Research, Society and Development, v. 10, n. 9, e46110918219, 2021

(CC BY 4.0) | ISSN 2525-3409 | DOI: http://dx.doi.org/10.33448/rsd-v10i9.18219

mesmo fato, ou fatos semelhantes - que podem ser considerados como má conduta científica ou desrespeito à integridade da pesquisa em um país e não em outro. Ou ainda: a sanção aplicada pode ser mais severa em um local do que em outro. Além disso, alguns pesquisadores trabalhando em um mesmo projeto, em cooperação internacional, podem ser punidos em seus países de origem, e outros não. Esta é uma situação de questionamento ético, bioético e legal que precisa de respostas.

Novos estudos sobre o mote deste artigo - integridade em pesquisa e má conduta científica - são necessários. Sugerese a realização de análises de políticas estabelecidas por instituições de pesquisa brasileiras, bem como de condutas de pesquisadores pátrios.

\section{Agradecimentos}

O presente trabalho foi realizado com apoio da Coordenação de Aperfeiçoamento de Pessoal de Nível Superior Brasil (CAPES) - Código de Financiamento 001.

\section{Referências}

Anderson, M. S. (2018) Shifting perspectives on Research Integrity. Journal of Empirical Research on Human Research Ethics, 13(5), 459-460.

Araújo, J. (2017) Má conduta científica: dados recentes e sua relação com a credibilidade científica. In: Cassimiro M, Diós-Borges MMP (Orgs.). Integridade Científica, Saúde Pública, Bioética e Educação em Saúde no Instituto Oswaldo Cruz (pp. 139-150). Editora Fi.

Armond, A. C. V., Gordijn, B., Lewis, J., Hossein, M., Bodnár, J. K., Holm, S. \& Kakuk, P. (2021). A scoping review of the literature featuring research ethics and research integrity cases. BMC Med Ethics, 22:50.

Bonn, N.A., Godecharle, S. \& Dierickx K. (2017). European Universities' Guidance on Research Integrity and Misconduct: Accessibility, Approaches, and Content. Journal of Empirical Research on Human Research Ethics, 12(1), 33-44.

Bouter, L. (2020). What Research Institutions Can Do to Foster Research Integrity. Science and Engineering Ethics, 26, 2363-2369.

Brasil. Conselho Nacional de Saúde. (2012) Resolução n. 466, de 12 de dezembro de 2012. http://conselho.saude.gov.br/resolucoes/2012/Reso466.pdf..

Brasil. Conselho Nacional de Saúde. (2016) Resolução n. 510, de 07 de abril de 2016. http://conselho.saude.gov.br/resolucoes/2016/Reso510.pdf

Brasil. (1940) Decreto-lei n. 2.848, de 07 de dezembro de 1940. Código Penal. http://www.planalto.gov.br/ccivil_03/decreto-lei/del2848compilado.htm

Brasil. (2008). Lei 11.794, de 8 de outubro de 2008. http://www.planalto.gov.br/ccivil_03/_ato2007-2010/2008/lei/111794.htm.

Bülow, W. \& Helgesson, G. (2019). Criminalization of scientific misconduct. Medicine, Health Care and Philosophy, 22:245-252.

Conselho Nacional de Desenvolvimento Científico e Tecnológico - CNpQ. Diretrizes básicas para a integridade na atividade científica. 2011. https://www.gov.br/cnpq/pt-br/composicao/comissao-de-integridade.

Coordenação de Aperfeiçoamento de Pessoal de Nível Superior - CAPES. (2011). Orientações Capes - Combate ao plágio. 04 de janeiro de 2011. file:///C:/Users/Monica/Downloads/Orientacao\%20Capes2011.Plagio\%20(1).pdf.

Davies, S. R. (2019). An Ethics of the System: Talking to Scientists About Research Integrity. Science and Engineering Ethics, $25: 1235-1253$.

Desmond. H. \& Dierickx, K. (2021). Research integrity codes of conduct in Europe: Understanding the divergences. Bioethics, 35:414-428.

Fundação de Amparo à Pesquisa do Estado de São Paulo (2014). Código de Boas Práticas Científicas. Fapesp.

Fundação Osvaldo Cruz. (2019). Guia de Integridade em Pesquisa da Fiocruz. Fiocruz.

Godecharle, S., Nemery, B. \& Dierickx, K. (2014). Heterogeneity in European Research Integrity Guidance: Relying on Values or Norms? Journal of Empirical Research on Human Research Ethics, 9(3), 79-90.

Hong Kong Principles. (2019). Disponível em: https://www.wcrif.org/guidance/hong-kong-principles. Acesso em 11 de julho de 2021.

Jia, H. (2018). China gets serious about research integrity. Disponível em: https://www.natureindex.com/news-blog/china-gets-serious-about-researchintegrity Acesso em 21 de fevereiro de 2021.

Larigot, L. (2019). Intégrité scientifique et recherche Vers un (ré)apprentissage pour prévenir les inconduites scientifiques involontaires? Med Sci, 35(8-9), 693-696.

Li, D. \& Cornelis, G. (2020) Defining and Handling Research Misconduct: A Comparison Between Chinese and European Institutional Policies. Journal of Empirical Research on Human Research Ethics, 15(4), 302-319. 
Research, Society and Development, v. 10, n. 9, e46110918219, 2021

(CC BY 4.0) | ISSN 2525-3409 | DOI: http://dx.doi.org/10.33448/rsd-v10i9.18219

Mejlgaard, N., Bouter, L. M., Gaskell, G., Kavouras, P., Allum, N., Bendtsen, A-K., Charitidis, C. A., Claesen, N., Dierickx, K., Domaradzka, A., Elizondo, A. R., Foeger, N., Hiney, M., Kaltenbrunner, W., Labib, K., Marušić, A., Sorensen, M. P., Ravn, T., Ščepanović, R., Tijdink J. K. \& Veltr, G. A. (2020). Research integrity: nine ways to move from talk to Walk. Nature, 586(7829),358-360.

Moher, D., Bouter, L., Kleinert, S., Glasziou, P., Sham, M. H., Barbour, V., Coriat, A-M., Foeger, N. \& Dirnagl, U. (2020) The Hong Kong Principles for assessing researchers: Fostering research integrity. PLoS Biol, 18(7), e3000737.

Montreal Statement on Research Integrity in Cross-Boundary Research Collaborations. (2013). https://wcrif.org/documents/354-montreal-statementenglish/file.

National Academies of Sciences, Engineering, and Medicine. (2017). Fostering Integrity in Research. The National Academies Press.

O'Gradymar, C. (2021) What is research misconduct? European countries can't agree. Science Magazine. https://www.sciencemag.org/news/2021/03/whatresearch-misconduct-european-countries-can-t-agree.

Pereira, A. S., Shitsuka, D. M., Parreira, F. J. \& Shitsuka, R. (2018). Metodologia da pesquisa científica. [e-book]. Santa Maria. Ed. UAB/NTE/UFSM.

Pickett, J. T. \& Roche, S. P. (2018). Questionable, objectionable or criminal? Public opinion on data fraud and selective reporting in science. Science and Engineering Ethics, 24, 151-171.

Rajkumar, S. V. \& Sampathkumar, P. (2020). Leaks of Clinical Trial Data and Research Integrity. Mayo Clin Proc., 95(7), 1318-1319.

Research integrity is much more than misconduct. (2019). Nature, 570(7759), 5.

Resnik, D. B., Neal, T., Raymond, A. \& Kissling, G. E. (2015). Research misconduct definitionsadopted by U.S. research institutions. Accountability in Research: Policies and Quality Assurance, 22(1), 14-21.

Resnik, D. B., Elliott, K. C., Soranno, P. A. \& Smith, E. M. (2017). Data-Intensive Science and Research Integrity. Accountability in Research, $24,344-358$.

Resnik, D. B. \& Elliott, K. C. (2019). Value-entanglement and the integrity of scientific research. Studies in History and Philosophy of Science, 75,1-11.

Revista FAPESP. Ética. Disponível em: https://revistapesquisa.fapesp.br/tag/etica/ Acesso em 20 de junho de 2021.

Shamoo, A. E. \& Resnik, D. B. (2015). Responsible Conduct of Research. 3rd ed. Oxford: Oxford University Press.

Silva, A.F. \& Coelho, K. (2020). Integridade académica e plágio. Como levar à mudança dentro e fora da sala de aula? In: Novo A, Nobre A, Simão J, Pereira P. (Coords.) Plágio e integridade académica na sociedade da informação. (pp. 68-77). Lisboa: Universidade Aberta.

Simões, E. (2018). A declaração de Singapura e a questão da integridade ética na pesquisa científica. Thaumazein, 11(22), 63-83.

Singapore Statement on Research Integrity. (2010). Disponível em: https://www.wcrif.org/documents/327-singapore-statement-a4size/file Acesso em: 30 de junho de 2021.

Steneck, N. H. (2007). ORI Introduction to the Responsible Conduct of Research. Rockville:US Dept. of Health and Human Services.

The European Code of Conduct for Research Integrity. (2017). Berlim: ALLEA - All European Academies.

Tijdink, J. K., Bouter, L. M., Veldkamp, C. L., van de Vem, P. M., Wicherts, J. M. \& Smulders, Y. M. (2016). Personality Traits Are Associated with Research Misbehavior in Dutch Scientists: A Cross-Sectional Study. PLoS One, 11, e0163251.

UK Research Integrity Office. (2020). Recommended Checklist for Research Communities During the COVID-19 Pandemic for both existing and new research. UK Research Integrity Office.

UK Research Integrity Office. (2009). Code of practice for research: Promoting good practice and preventing misconduct. UK Research Integrity Office.

UK Research and Innovation. (2013). UKRI Policy and Guidelines on Governance of Good Research Conduct. https://www.ukri.org/wpcontent/uploads/2021/03/UKRI-050321-PolicyGuidelinesGovernanceOfGoodResearchConduct.pdf

United States. (2000) Office of Science and Technology Policy. Notification of Final Policy. https://www.govinfo.gov/content/pkg/FR-2000-12-06/pdf/0030852.pdf .

United States. (2020). The Office of Research Integrity (ORI). https://ori.hhs.gov/about-ori. 